\title{
Abnormal cardiopulmonary exercise variables in asymptomatic relatives of patients with dilated cardiomyopathy who have left ventricular enlargement
}

\author{
N G Mahon, S Sharma, P M Elliott, M K Baig, M W Norman, S Barbeyto, \\ W J McKenna
}

\begin{abstract}
Background-Left ventricular enlargement with normal systolic function is common in asymptomatic relatives of patients with familial dilated cardiomyopathy, many of whom progress to overt dilated cardiomyopathy at follow up.

Objective-To examine maximal and submaximal gas exchange variables of cardiopulmonary exercise testing in asymptomatic relatives with left ventricular enlargement.

Design and setting-Controlled evaluation of metabolic exercise performance of patients with dilated cardiomyopathy and asymptomatic relatives with left ventricular enlargement identified through prospective family screening in a cardiomyopathy outpatient clinic.

Methods-23 relatives with left ventricular enlargement, 33 normal controls, 29 patients with dilated cardiomyopathy, and 10 elite athletes with echocardiographic criteria of left ventricular enlargement ("physiological" enlargement) underwent symptom limited upright cycle ergometry using a ramp protocol.

Results-Peak oxygen consumption $\left(\mathrm{p}_{\mathrm{V}} \mathrm{O}_{2}\right.$; mean (SD)) was significantly reduced in relatives with left ventricular enlargement $(78(16.3) \%) v$ normal controls $(96 \%, \mathrm{p}<0.01)$ and athletes $(152 \%, \mathrm{p}<0.001)$, but was higher than in patients with dilated cardiomyopathy $(69 \%, \mathrm{p}<0.01)$. $\mathrm{p} \overline{\mathrm{V}} \mathrm{O}_{2}$ was less than $80 \%$ of predicted in $75 \%$ of patients, $58 \%$ of relatives, $22 \%$ of controls, and none of the athletes. Oxygen pulse ( $\mathrm{p} \overline{\mathrm{V}}_{2}$ /heart rate) was less than $80 \%$ of predicted in $69 \%$ of patients, $35 \%$ of relatives, $6 \%$ of controls, and none of the athletes. The slope of minute ventilation $v \mathrm{CO}_{2}$ production $\left(\Delta \mathrm{VE} / \Delta \overline{\mathrm{V}} \mathrm{CO}_{2}\right)$ was $>30$ in $68 \%$ of patients, $50 \%$ of relatives, and in none of the controls or athletes. Anaerobic threshold, occurring in relatives at 37 (14) $\%$ of the predicted $\overline{\mathrm{V}}_{2}$, was higher than in the patients $(32 \%, \mathrm{p}<0.01)$ and lower than in the controls $(45 \%, \mathrm{p}<0.05)$ or in the athletes $(55 \%, \mathrm{p}<0.001)$.

Conclusions-Maximal and submaximal cardiopulmonary exercise test variables are abnormal in asymptomatic relatives with left ventricular enlargement, in spite of normal systolic function. This provides further evidence that left ventricular enlargement represents subclinical disease in relatives of patients with dilated cardiomyopathy. Metabolic exercise testing can complement echocardiography in identifying relatives at risk for the development of dilated cardiomyopathy. (Heart 2000;83:511-517)
\end{abstract}

Keywords: cardiomyopathy; exercise; diagnosis

Idiopathic dilated cardiomyopathy usually develops insidiously and is often advanced at the time of diagnosis. Thus prognosis among patients referred to hospital is poor, with a $25-30 \%$ one year mortality and a $50 \%$ five year mortality. ${ }^{1}$ The ability to identify early disease would be a significant advance in the current management of this disease and facilitate studies of its pathogenesis.

Evaluation of families of patients with dilated cardiomyopathy has identified a subset of relatives who have left ventricular enlargement (defined as a left ventricular diastolic dimension (LVEDD) of $>112 \%$ of that predicted for age and body surface area ${ }^{2}$ in the presence of normal systolic function, and in the absence of an underlying cause such as hypertension or athletic training. ${ }^{3}$ ) Left ventricular enlargement in a relative of a patient with dilated cardiomyopathy may be a marker of early or mild disease. Relatives with left ventricular enlargement have a higher than expected prevalence of circulating heart spe- cific antibodies, as well as raised circulating cytokines and cardiac creatine kinase isoforms. ${ }^{5}$ A recent three year follow up study showed that overt dilated cardiomyopathy develops in $27 \%$ of patients with left ventricular enlargement. ${ }^{6}$

Patients with dilated cardiomyopathy have abnormal maximal and submaximal responses to cardiopulmonary exercise testing, ${ }^{7}$ involving both central and peripheral factors. ${ }^{8}$ We hypothesised that asymptomatic left ventricular enlargement in the relatives of such patients would be accompanied by abnormalities of cardiopulmonary exercise capacity, in contrast to cardiopulmonary performance in individuals with physiological left ventricular enlargement caused by athletic training. Our aim in this study was thus to examine maximal and submaximal responses to cardiopulmonary exercise testing in those relatives of cardiomyopathy patients found to have left ventricular enlargement, and to compare them with patients with overt dilated cardiomyopathy, 
normal controls, and athletes with "physiological" dilatation of the left ventricle as a result of training.

\section{Methods}

PATIENTS

Twenty three consecutive asymptomatic relatives with left ventricular enlargement, from 19 families attending a tertiary referral centre between July 1997 and March 1998, underwent metabolic exercise testing. They were compared with 29 unrelated patients with dilated cardiomyopathy being followed up during the same period. Evaluation of asymptomatic relatives was performed with local ethics committee approval and has been described in detail elsewhere. ${ }^{6}$ Left ventricular enlargement was defined as an unexplained left ventricular end diastolic dimension (LVEDD) of more than $112 \%$ of predicted in the presence of a shortening fraction of greater than $25 \%{ }^{6}$ Predicted left ventricular end diastolic dimension (LVEDDc) was calculated according to the formula of Henry and colleagues ${ }^{2}$ : LVEDDc $=\left[45.3 \times \mathrm{BSA}^{0.3}\right]-[0.03 \times$ age $]-$ 7.2 , where $\mathrm{BSA}=$ body surface area. The measured LVEDD was then expressed as a percentage according to the ratio: LVEDD $\%=$ LVEDD/LVEDDc. Dilated cardiomyopathy was defined according to World Health Organization criteria ${ }^{9}$; in addition, all patients with dilated cardiomyopathy had an LVEDD of $>112 \%$ of predicted, with a shortening fraction of $<25 \%$. Patients with coronary disease, hypertension, valvar disease, or a regular alcohol intake of $>21$ units/week in men and > 14 units/week in women were excluded. All relatives with left ventricular enlargement filled in a questionnaire about their daily physical activity.

CONTROLS

Forty five volunteers with a normal 12 lead ECG and echocardiogram underwent metabolic exercise testing under identical conditions. All volunteers were required to fill in a questionnaire about their daily physical activity. Individuals performing more than two hours of organised physical training a week were excluded as controls.

Ten healthy elite endurance athletes who fulfilled echocardiographic criteria for left ventricular enlargement were also evaluated. An elite athlete was defined as an individual who had attained a sufficiently high standard in his or her sport to compete at international level.

\section{ECHOCARDIOGRAPHY}

All subjects underwent conventional two dimensional echocardiography less than six weeks before the exercise test. End diastolic and end systolic diameters were measured from the short axis views at the level of the tips of the mitral valve leaflets, and shortening fraction was derived from these measurements. ${ }^{10}$ All echocardiograms were analysed blind to the clinical diagnosis. All patients with dilated cardiomyopathy and left ventricular enlargement underwent clinical assessment, 12 lead ECG, and 24 hour Holter monitoring.

EXERCISE

All patients and controls were fasted for two hours before exercise testing. Exercise was performed in the upright position on a Sensormedics ergometrics $800 \mathrm{~S}$ cycle ergometer (Ergoline, Bitz, Germany), using a ramp protocol ranging from 10-15 watts/min (selected to ensure adequate stress and avoid premature fatigue) in a quiet air conditioned room with an average temperature of $21^{\circ} \mathrm{C}$ and full resuscitation facilities. Each test was supervised by an experienced cardiologist, nurse, and senior technician.

Before the test all patients underwent a three minute practice run at zero work rate. A respiratory exchange ratio below 0.85 was required before starting the test. Simultaneous breath by breath gas exchange analysis was performed using a dedicated Sensormedics metabolic cart (V Max 29 Console, Sensormedics, Yorba Linda, California, USA). Respiratory gas was sampled continuously from a mouthpiece and analysed using a $1111 \mathrm{D} / 000$ paramagnetic transducer for oxygen and a 2900 MMC nondispersive infrared sensor for carbon dioxide. The signals underwent analogue to digital conversion for the calculation of oxygen consumption $\left(\overline{\mathrm{V}}_{2}\right)$ and carbon dioxide production $\left(\overline{\mathrm{V}} \mathrm{CO}_{2}\right)$ using an established technique. ${ }^{11}$ Measurements included $\overline{\mathrm{V}} \mathrm{O}_{2}(1 / \mathrm{min}), \overline{\mathrm{V}} \mathrm{CO}_{2}(1 / \mathrm{min})$, minute ventilation (VE), heart rate (beats/ min), work rate (WR; watts), and respiratory quotient. Graphs of $\overline{\mathrm{V}} \mathrm{O}_{2} v \overline{\mathrm{V}} \mathrm{CO}_{2}$ to calculate anaerobic threshold, $\overline{\mathrm{V}}_{2} v$ work rate to calculate aerobic work efficiency, $\mathrm{VE} v \overline{\mathrm{V}}_{2}$, oxygen pulse $v \overline{\mathrm{V}} \mathrm{O}_{2}$, and heart rate $v \overline{\mathrm{V}}_{2}$ were generated by an IBM computer (Sensormedics Vmax/Vision software) using on line gas exchange data from the metabolic cart, each variable being plotted at 10 second intervals. Signals from a 12 lead ECG were displayed continuously and recorded at two minute intervals using a Marquette ECG recorder (Marquette Electronics Inc, Milwaukee, Wisconsin, USA). Blood pressure was measured by auscultation at the brachial artery at one minute intervals during exercise and for the first three minutes after exercise, using a mercury sphygmomanometer.

METABOLIC INDICES: DEFINITIONS AND PREDICTED VALUES

The peak oxygen consumption $\left(\mathrm{p} \overline{\mathrm{V}}_{2}\right)$, defined as the highest oxygen consumption achieved during exercise, was calculated by measuring the mean of the highest values over the last 10 seconds of exercise. To allow for age, body size, and sex differences, ${ }^{12}$ results were expressed as a percentage of the predicted maximum oxygen consumption ( $\left.\overline{\mathrm{V}}_{2} \mathrm{max}\right)$, which was calculated using established nomograms based on age, sex, height, and weight. ${ }^{13-15}$ Values below $80 \%$ fall below established 95\% confidence limits and were considered abnormal. ${ }^{16}$ The anaerobic threshold was calculated non-invasively using the $\mathrm{V}$ slope method ${ }^{17}$ and expressed as a percentage of the predicted $\overline{\mathrm{V}}_{2}$ max. Values 
under $40 \%$ were considered abnormal. ${ }^{18}$ The oxygen pulse $\left(\mathrm{O}_{2}\right.$ pulse) was calculated as the quotient of the $\mathrm{p} \overline{\mathrm{VO}}_{2}$ and peak heart rate. Values were expressed as a percentage of the maximum predicted $\mathrm{O}_{2}$ pulse calculated from formulae for predicted $\overline{\mathrm{V}} \mathrm{O}_{2} \mathrm{max}$ and predicted maximum heart rate. ${ }^{19}$ Values below $80 \%$ of predicted were considered abnormal. Values above $80 \%$ were regarded as normal provided the individual had achieved a maximum heart rate of at least $80 \%$. The work rate (WR) in watts at peak exercise was determined and expressed as a percentage of the predicted maximum work rate calculated according to formulae based on age, sex, height, and weight. $^{2021}$

Expired volume $v$ expired $\mathrm{CO}_{2}$ was plotted graphically, and the relation $\left(\Delta \mathrm{VE} / \Delta \overline{\mathrm{V}} \mathrm{CO}_{2}\right)$ was calculated as the slope below the point of anaerobic threshold. The normal gradient of the slope is $26-30 .^{22} \mathrm{~A}$ respiratory quotient of less than 1.1 was considered to indicate submaximal effort, and such subjects were excluded from the study. Six patients with dilated cardiomyopathy and two relatives with left ventricular enlargement were excluded on this basis.

\section{STATISTICAL ANALYSIS}

Statistical analysis was performed using SPSS for Windows (SPSS Inc, Chicago, Illinois, USA). All variables were tested for normality of distribution using the one sample Kolmogorov-Smirnov test. Unpaired Student's $t$ test, analysis of variance, $\chi^{2}$ test, Mann-Whitney U test, Kruskall-Wallis test, and bivariate correlation tests were used where appropriate. A value of $p<0.05$ was considered significant. Metabolic and echocardiographic results were expressed as absolute values and as percentages of predicted values to minimise differences resulting from age and sex disparities. Results are expressed as mean (SD).

\section{Results}

All 103 patients and controls underwent exercise testing without complication. Seventy per cent of athletes, $69 \%$ of patients with dilated cardiomyopathy, $60 \%$ of relatives with left ventricular enlargement, and $67 \%$ of normal controls were male. Mean (SD) age was 26 (12.2) years in athletes (range 15-54), 46 (12.6) years in patients (19-70), 32 (12.6) years in relatives (17-62), and 34 (12.8) years in controls (15-66). Two relatives with left ventricular enlargement who undertook more than two hours of structured physical activity a week were included in the analysis.

ECHOCARDIOGRAPHIC DATA

Baseline echocardiographic data for all four groups are shown in table 1. Mean (SD) LVEDD \% in relatives with left ventricular enlargement was 118.4 (5). This did not differ significantly from LVEDD \% of either athletes or patients with dilated cardiomyopathy, but was higher than in normal controls $(p<0.001)$. Fractional shortening (FS) in relatives with left ventricular enlargement was $31(4.4) \%$; this was lower than in normal controls $(37(5.3) \%, \mathrm{p}<0.001)$ and higher than in the patients $(17(4.4) \%, \mathrm{p}<0.001)$.

CLINICAL FEATURES OF PATIENTS WITH LEFT VENTRICULAR ENLARGEMENT AND DILATED CARDIOMYOPATHY

Most of the patients with dilated cardiomyopathy were in New York Heart Association (NYHA) functional class I (10 (36)\%) or II (16 (54)\%); three patients $(10 \%)$ were in class III. The patients were all symptomatic at presentation. All of them were on angiotensin converting enzyme inhibitors, $45 \%$ were on diuretics, $54 \%$ on digoxin, $55 \%$ on warfarin, $20 \%$ on amiodarone, $10 \%$ on $\beta$ blockers, and $7 \%$ on angiotensin II antagonists. All the relatives were asymptomatic and none was receiving cardiac drugs.

Nineteen of the patients with cardiomyopathy $(66 \%)$ were in sinus rhythm and $10(34 \%)$ had atrial fibrillation; six (20\%) had left axis deviation on the ECG, and five (17\%) had left bundle branch block. Non-sustained ventricular tachycardia (three or more ventricular ectopic beats at a rate of $\geqslant 120$ beats/min) was

Table 1 Echocardiographic and metabolic exercise data (all groups)

\begin{tabular}{|c|c|c|c|c|c|c|c|c|c|c|c|}
\hline & \multicolumn{2}{|l|}{$L V E$} & \multicolumn{3}{|l|}{$D C M$} & \multicolumn{3}{|c|}{ Normal } & \multicolumn{3}{|c|}{ Athlete LVE } \\
\hline & Mean & $S D$ & Mean & $S D$ & $p$ Value $^{*}$ & Mean & $S D$ & $p$ Value $^{\star}$ & Mean & $S D$ & p Value * \\
\hline Age (years) & 32 & 13 & 46 & 13 & $<0.001$ & 34 & 13 & NS & 26 & 12 & NS \\
\hline FS & 31 & 4 & 17 & 4 & $<0.001$ & 37 & 5 & $<0.001$ & 35 & 7 & NS \\
\hline LVEDD $(\%) \dagger$ & 118 & 5 & 129 & 11 & NS & 104 & 6.3 & $<0.001$ & 117 & 4 & NS \\
\hline AT & 37 & 14 & 32 & 11 & $<0.01$ & 45 & 12 & $<0.05$ & 55 & 10 & $<0.001$ \\
\hline HRmax (beats/min) & 166 & 21 & 153 & 28 & $<0.05$ & 172 & 15 & NS & 180 & 12 & NS \\
\hline HRmax $(\%) \dagger$ & 93 & 10 & 90 & 15 & NS & 97 & 7 & NS & 98 & 6 & NS \\
\hline $\mathrm{O}_{2}$ pulse & 12 & 4 & 9 & 3 & $<0.01$ & 13 & 3 & NS & 23 & 5 & $<0.001$ \\
\hline $\mathrm{O}_{2}$ pulse $(\%) \dagger$ & 89 & 17 & 70 & 23 & $<0.01$ & 105 & 20 & $<0.05$ & 167 & 41 & $<0.001$ \\
\hline RQ (peak exercise) & 1 & 0 & 1 & 0 & NS & 1 & 0 & NS & 1 & 0 & NS \\
\hline $\mathrm{VE} / \overline{\mathrm{V}} \mathrm{CO}_{2}$ & 30 & 6 & 34 & 6 & $<0.05$ & 27 & 4 & $<0.05$ & 24 & 3 & $<0.01$ \\
\hline $\mathrm{p} \overline{\mathrm{V}} \mathrm{O}_{2}(\mathrm{ml} / \mathrm{kg} / \mathrm{min})$ & 27 & 10 & 18 & 6 & $<0.001$ & 32 & 8 & $<0.001$ & 56 & 8 & $<0.001$ \\
\hline $\mathrm{p} \overline{\mathrm{V}} \mathrm{O}_{2}(\%) \dagger$ & 78 & 16 & 69 & 19 & $<0.01$ & 96 & 18 & $<0.01$ & 152 & 35 & $<0.001$ \\
\hline Work (watts) & 165 & 63 & 123 & 54 & $<0.001$ & 197 & 61 & $<0.001$ & 324 & 48 & $<0.001$ \\
\hline Work $(\%) \dagger$ & 82 & 21 & 63 & 24 & $<0.01$ & 104 & 21 & $<0.01$ & 156 & 34 & $<0.001$ \\
\hline $\mathrm{PET} \mathrm{CO}{ }_{2}$ & 39 & 5 & 35 & 5 & NS & 38 & 4 & NS & 38 & 4 & NS \\
\hline
\end{tabular}

${ }^{\star}$ Comparison with LVE group.

†Per cent of normal standard.

AT, anaerobic threshold (\% of predicted $\bar{V}_{\mathrm{O}_{2}} \max$ ); DCM, dilated cardiomyopathy; FS, fractional shortening; HRmax, maximum heart rate; LVE, left ventricular enlargement; LVEDD, left ventricular end diastolic dimension; $\mathrm{O}_{2}$ pulse, quotient of $\mathrm{p} \overline{\mathrm{V}}_{2}$ and peak heart rate; $\mathrm{p} \overline{\mathrm{V}}_{2}$, peak oxygen consumption; $\mathrm{PET} \mathrm{CO}$, pressure of end tidal carbon dioxide; $\mathrm{RQ}$, respiratory quotient; $\mathrm{VE}$, minute ventilation. 
documented at initial assessment in 11 (39\%) of the patients. The asymptomatic subjects with left ventricular enlargement were all in sinus rhythm. The relatives with left ventricular enlargement all had normal ECGs.

\section{EXERCISE VARIABLES}

Metabolic exercise variables are shown for all four groups in table 1. Maximum heart rate (per cent predicted) in the relatives did not differ significantly from controls or athletes but was higher than in the patients (92 (9.8)\% v 89 $(15) \%, p=0.02)$. Relatives achieved $83(20) \%$ of their predicted maximum work rate $v 63 \%$ $(\mathrm{p}<0.004)$ in the patients, $104 \%(\mathrm{p}=0.001)$ in normal controls, and $156 \%(\mathrm{p}<0.001)$ in athletes. Similar significant differences were observed when absolute values (beats/min and watts respectively) were analysed (table 1 ).

Oxygen pulse

The results are shown in fig 1 . Oxygen pulse in the relatives was 89 (17)\% of predicted, which was lower than that observed in normal controls $(105 \%, \mathrm{p}<0.05)$ and athletes $(167 \%, p<0.001)$, and higher than in the patients $(70 \%, \mathrm{p}<0.01) . \mathrm{O}_{2}$ pulse was less than $80 \%$ of predicted in $69 \%$ of the patients, in $35 \%$ of the relatives, in $6 \%$ of the controls, and in none of the athletes (table 2). One patient and one relative had an $\mathrm{O}_{2}$ pulse that appeared normal in spite of a low $\mathrm{p} \overline{\mathrm{V}} \mathrm{O}_{2}$, because of a low maximum heart rate. In $40 \%$ of the patients and $46 \%$ of the relatives the oxygen pulse did not increase in the expected parabolic pattern ${ }^{23}$ but began to plateau below the anaerobic threshold. In these patients, heart rate increased more rapidly at the point of flattening.

Peak oxygen uptake

The results are shown in fig $2 . \mathrm{p} \overline{\mathrm{V}} \mathrm{O}_{2}$ as a percentage of the predicted $\overline{\mathrm{V}} \mathrm{O}_{2} \mathrm{max}$ was significantly reduced in the relatives (78 (16.3)\%) compared with the normal controls $(96 \%, \mathrm{p}<0.01)$ and the athletes $(152 \%$, $\mathrm{p}<0.001)$, and was higher than in the patients $(69 \%, \mathrm{p}<0.01)$. Similar significant differences were observed when absolute values in $\mathrm{ml} / \mathrm{kg} /$ min were analysed (table 1 ). Peak oxygen consumption was less than $80 \%$ in $76 \%$ of the patients, in $58 \%$ of the relatives, in $22 \%$ of the controls, and in none of the athletes (table 2).

\section{$\triangle V E / \triangle \bar{V} C O_{2}$}

The results are shown in fig 3 . The slope of the minute ventilation as a function of $\overline{\mathrm{V}} \mathrm{CO}_{2}$ below anaerobic threshold $\left(\Delta \mathrm{VE} / \Delta \overline{\mathrm{V}} \mathrm{CO}_{2}\right)$ was increased in the patients, with a mean value of 34 (6.2). The mean $\Delta \mathrm{VE} / \Delta \overline{\mathrm{V}} \mathrm{CO}_{2}$ slope was normal in controls and at the upper limit of normal in the relatives. Sixty eight per cent of the patients and $50 \%$ of the relatives had a $\Delta \mathrm{VE} / \Delta \overline{\mathrm{V}} \mathrm{CO}_{2}$ slope of $>30$. No normal controls and no athletes had a value above 30 (table 2).

Anaerobic threshold

The results are shown in fig 4. Anaerobic threshold occurred at a mean of $37(14) \%$ of the predicted $\overline{\mathrm{V}}_{2} \mathrm{max}$ in the relatives, which was higher than in the patients $(32 \%$, $\mathrm{p}=0.004$ ) and lower than in the normal controls $(45 \%, \mathrm{p}=0.02)$ or the athletes $(55 \%$, $\mathrm{p}<0.001)$. Anaerobic threshold occurred at less than $40 \%$ of the predicted $\overline{\mathrm{V}}_{2}$ max in $75 \%$ of the patients, $65 \%$ of the relatives, $22 \%$ of the controls, and none of the athletes (table 2).

CORRELATION BETWEEN ECHOCARDIOGRAPHIC DIMENSIONS, METABOLIC VARIABLES, AND FUNCTIONAL CLASS

When all 103 subjects were analysed together, modest correlations were observed between fractional shortening and $\mathrm{O}_{2}$ pulse $(r=0.49$,

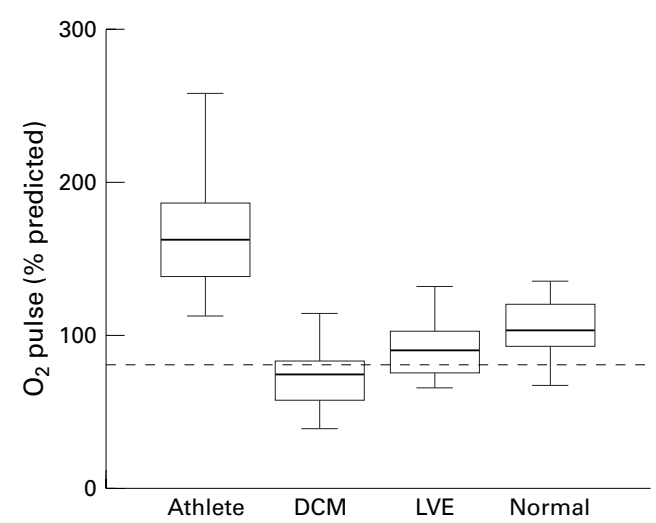

Figure 1 Boxplot of oxygen pulse values for each group, showing median, quartiles, and 95th centiles. Dashed line represents $80 \%$ of predicted oxygen pulse.

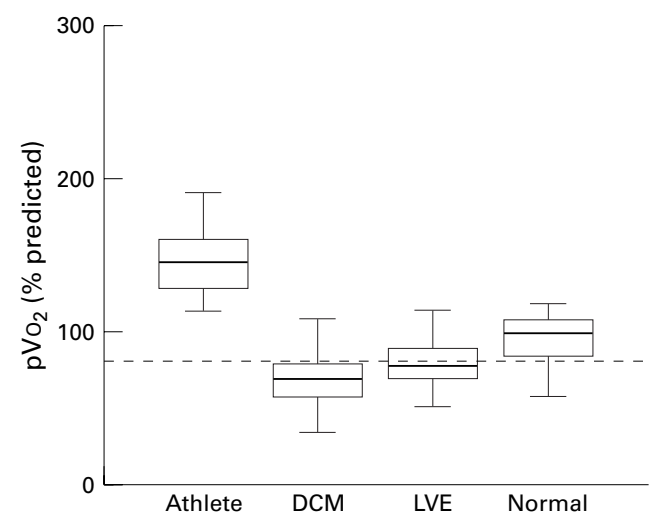

Figure 2 Boxplot of $p \overline{\mathrm{V}} \mathrm{O}_{2}$ per cent predicted for each group, showing median, quartiles, and 95 th centiles. Dashed line represents $80 \%$ of predicted $p \bar{V} O_{2}$.

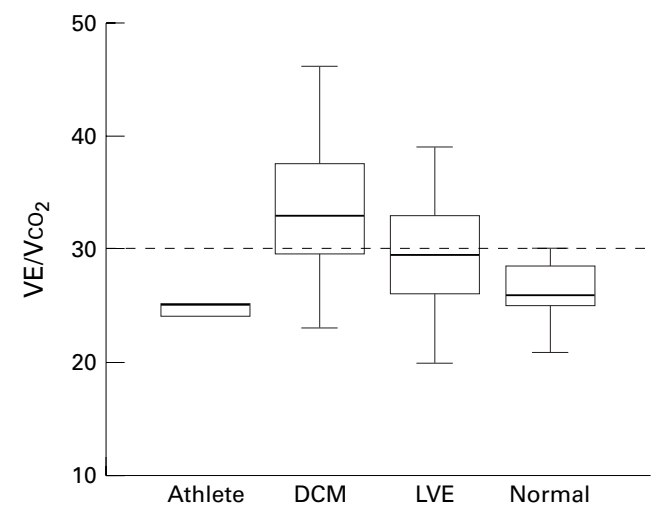

Figure 3 Boxplot of $\triangle V E / \Delta \bar{V} C_{2}$, slope for each group, showing median, quartiles, and 95th centiles. Dashed line represents the normal slope of 30 . 
Table 2 Prevalence of abnormal results within each group

\begin{tabular}{llccl}
\hline & $\begin{array}{l}\text { DCM } \\
(\%)\end{array}$ & $\begin{array}{c}\text { LVE } \\
(\%)\end{array}$ & $\begin{array}{l}\text { Normal } \\
(\%)\end{array}$ & $\begin{array}{l}\text { Athletes } \\
(\%)\end{array}$ \\
\hline $\mathrm{HRmax}(\%)<80^{\star}$ & 25 & 9 & 3 & 0 \\
$\mathrm{AT}<40^{\star}$ & 75 & 65 & 22 & 0 \\
$\mathrm{O}_{2}$ pulse $(\%)<80^{\star}$ & 69 & 35 & 6 & 0 \\
$\mathrm{VE} / \overline{\mathrm{V}} \mathrm{CO}_{2}>30$ & 68 & 50 & 0 & 0 \\
Work (watts) $<80^{\star}$ & 79 & 50 & 10 & 0 \\
$\mathrm{p} \overline{\mathrm{V}} \mathrm{O}_{2}<80^{\star}$ & 76 & 58 & 22 & 0
\end{tabular}

*Per cent predicted.

AT, anaerobic threshold; DCM, dilated cardiomyopathy; HRmax, maximum heart rate; LVE, left ventricular enlargement; $\mathrm{O}_{2}$ pulse, quotient of $\mathrm{p} \overline{\mathrm{V}}_{2}$ and peak heart rate; $\mathrm{p} \overline{\mathrm{V}}_{2}$, peak oxygen consumption; $\mathrm{VE}$, minute ventilation.

$\mathrm{p}<0.001), \quad \overline{\mathrm{V}} \mathrm{O}_{2} \max \quad(r=0.47, \mathrm{p}<0.001)$, $\mathrm{VE} / \overline{\mathrm{V}} \mathrm{CO}_{2} \quad(r=-0.49, \mathrm{p}<0.001)$, maximum heart rate $(r=0.29, \mathrm{p}=0.01)$, anaerobic threshold $(r=0.42, \mathrm{p}<0.001)$, NYHA class $(r=-0.50, \mathrm{p}<0.001)$, and WR\% $(r=0.53$, $\mathrm{p}<0.001)$. LVEDD $\%$ correlated poorly with metabolic measurements, even when athletes were excluded from analysis.

\section{Discussion}

The results show that asymptomatic relatives of patients with dilated cardiomyopathy, and who also have left ventricular enlargement, have significantly abnormal cardiopulmonary exercise test results. This adds to the serological and immunological evidence that left ventricular enlargement represents early disease in some individuals. While the mechanisms of abnormal responses remain speculative, this study suggests that both cardiac and peripheral mechanisms may be responsible.

LEFT VENTRICULAR FUNCTION IN LEFT

VENTRICULAR ENLARGEMENT

Although baseline systolic function was normal in the relatives, analysis of the oxygen pulse pattern suggests that abnormalities of cardiopulmonary exercise measurements may be caused by impaired augmentation of systolic function in response to exercise. Oxygen pulse is the product of stroke volume and arteriovenous oxygen difference. ${ }^{16}$ The peak oxygen pulse was abnormally low in $35 \%$ of the relatives. In $46 \%$ of the relatives (compared with $40 \%$ of the patients) the oxygen pulse started to plateau with increasing work rate instead of rising in its normal parabolic fashion. One possible mechanism for an early plateau of oxygen pulse is the failure of stroke volume to increase. In patients with dilated cardiomyopathy and left ventricular enlargement who had abnormally flat oxygen pulse responses, the plateau occurred at or shortly after the anaerobic threshold. This phenomenon has previously been described in patients with hypertrophic cardiomyopathy ${ }^{23}$ and may be caused by the early development of metabolic acidaemia because of a depressed stroke volume response. ${ }^{24}$

PERIPHERAL MECHANISMS

An alternative explanation for the reduced $\mathrm{p} \overline{\mathrm{V}} \mathrm{O}_{2}$ and oxygen pulse in the relatives would be a reduction in arteriovenous oxygen difference in these individuals. Alterations that could affect peripheral oxygen consumption- including changes in peripheral blood flow, ratios of type I to type II muscle fibres, and mitochondrial density, which are observed in patients with dilated cardiomyopathy and heart failure ${ }^{25} 26$ - may also occur in left ventricular enlargement. However, as arteriovenous oxygen difference is generally increased in heart failure in spite of the changes described above, a reduction in the relatives is unlikely.

$\Delta \mathrm{VE} / \Delta \overline{\mathrm{V}} \mathrm{CO}_{2}$

Analysis of the $\Delta \mathrm{VE} / \Delta \overline{\mathrm{V}} \mathrm{CO}_{2}$ slope also raises the possibility of peripheral mechanisms for reduced exercise performance in relatives with left ventricular enlargement. While mean $\Delta \mathrm{VE} /$ $\Delta \overline{\mathrm{V}} \mathrm{CO}_{2}$ was normal in the relatives, $46 \%$ had a slope of $>30$. A raised $\Delta \mathrm{VE} / \Delta \overline{\mathrm{V}} \mathrm{CO}_{2}$ is well documented in patients with congestive cardiac failure, ${ }^{27-29}$ but the mechanisms of this increased ventilatory response are controversial. Ventilation-perfusion mismatch reflecting increased pulmonary dead space caused by pulmonary vascular abnormalities has been proposed..$^{30}$ This is supported by the finding that end tidal $\mathrm{CO}_{2}$ was normal in all patients in this study. However, relatives with left ventricular enlargement who do not have heart failure are unlikely to have pulmonary vascular abnormalities. Other mechanisms that may be involved include augmented chemosensitivity, ${ }^{31}$ an enhanced ergoreflex causing direct stimulation of ventilation by muscle activity, ${ }^{32}$ and reduced ability to increase gas transfer on exercise. ${ }^{33}$ Similar reflexes may be involved in the regulation of peripheral blood flow and could be responsible for the abnormal oxygen pulse patterns, anaerobic threshold, and $\Delta \overline{\mathrm{V}} \mathrm{O}_{2} /$ $\Delta$ WR relation seen in the relatives. This suggests that asymptomatic relatives may not only be developing subtle cardiac abnormalities but also have more widespread changes affecting cardiovascular performance.

\section{COMPARISON WITH LEFT VENTRICULAR}

\section{ENLARGEMENT IN ATHLETES}

The contrast between results obtained in the relatives and in the athletes reinforces the view that left ventricular enlargement in relatives is an indicator of underlying pathology. Left ventricular enlargement in athletes is common and represents a normal physiological response to intensive physical training. Of 515 elite athletes evaluated at this institution, $32 \%$ had echocardiographic criteria of left ventricular enlargement. ${ }^{34}$ The high peak oxygen consumption observed in athletes with left ventricular enlargement who underwent cardiopulmonary exercise testing suggests that it is not the ventricular enlargement per se that is responsible for the cardiopulmonary abnormalities observed in the relatives, and furthermore that metabolic exercise testing may be a useful method of distinguishing physiological from pathological left ventricular enlargement.

\section{LIMITATIONS}

The definition of left ventricular enlargement as "enlargement with normal systolic function" should be qualified by the recognition that while systolic function is within normal limits 
in these patients it is lower than in normal controls $(30 \% v 35 \%)$. Therefore early or mild dilated cardiomyopathy is not manifested exclusively by dilatation but is accompanied by evidence of a decline in systolic function, which nonetheless remains within normal limits, such that left ventricular enlargement is the more striking finding. Isolated depressed fractional shortening is also a recognised finding when relatives are evaluated, but this is less common and is not clearly associated with risk of progression.

Maximum (and hence peak) oxygen consumption is normally distributed within the population. As a result, overlap between groups is evident from the data. However, statistical analysis shows that metabolic indices in each group lie on a continuum, with athletes at one end and patients with cardiomyopathy at the other. The intermediate location of relatives with left ventricular enlargement, between normal controls and patients, is consistent with the hypothesis that left ventricular enlargement represents mild or early dilated cardiomyopathy. Because of this tendency for $\mathrm{p} \overline{\mathrm{V}} \mathrm{O}_{2}$ to be normally distributed, metabolic exercise testing cannot in isolation identify abnormal relatives, but may provide useful additional information in the appropriate clinical context. Relatives with left ventricular enlargement who performed more than two hours of organised physical activity a week were not specifically excluded from our analysis. This could have biased this group towards better metabolic indices, in contrast to the controls in whom this was a specific exclusion criterion. The two relatives who exceeded this level of activity had a $\mathrm{p} \overline{\mathrm{V}} \mathrm{O}_{2}$ of $95 \%$ and $80.5 \%$, respectively. In contrast, the lowest $\mathrm{p} \overline{\mathrm{V}} \mathrm{O}_{2}$ among the athletes with left ventricular enlargement was $114 \%$ of predicted.

Finally, although the use of cycle ergometry may have limited the attainable $\mathrm{p} \overline{\mathrm{V}}_{2}$, particularly among athletes, all predicted values were adjusted for the mode of exercise.

\section{CONCLUSIONS}

Although systolic function is within normal limits, asymptomatic relatives with left ventricular enlargement have significant abnormalities on metabolic exercise testing. Analysis of maximal and submaximal variables suggests that mechanisms similar to those in more advanced disease may be involved, including alterations in ventilatory reflexes. These abnormalities contrast with the supranormal results in athletes, who have a similar degree of left ventricular enlargement. This adds to serological and immunological evidence that left ventricular enlargement represents early or mild disease in some individuals. Metabolic exercise testing could form part of a clinical algorithm for the detection and risk stratification of relatives who have early dilated cardiomyopathy.

We gratefully acknowledge the assistance of Mary Gould, Carol Page, and Brian Mist. Sanjay Sharma and Mark W Norman were supported by British Heart Foundation junior fellowships.
1 Diaz RA, Obasohan O, Oakley CM. Prediction of outcome in dilated cardiomyopathy. Br Heart f 1987;58:393-9.

2 Henry WL, Gardin JM, Ware JH. Echocardiographic measurements in normal subjects from infancy to old age. Circu lation 1980;62:1054-61.

3 Michels VV, Moll PP, Miller FA, et al. The frequency of familial dilated cardiomyopathy in a series of patients with idiopathic dilated cardiomyopathy. N Engl F Med 1992;326: $77-82$.

4 Keeling PJ, Gang Y, Seo H, et al. Familial dilated cardiomyopathy in the United Kingdom. Br Heart f 1995;73:41721 .

5 Marriott JB, Goldman JH, Keeling PJ, et al. Abnormal cytokine profiles in patients with idiopathic dilated cardiomy-
opathy and their asymptomatic relatives. Heart 1996;75: opathy and

6 Baig MK, Goldman JH, Caforio AL, et al. Familial dilated cardiomyopathy: cardiac abnormalities are common in asymptomatic relatives and may represent early disease. $\mathcal{F}$ Am Coll Cardiol 1998;31:195-201.

7 Chua TP, Ponikowski P, Harrington D, et al. Clinical correlates and prognostic significance of the ventilatory response to exercise in chronic heart failure. F Am Coll Cardiol 1997; 29:1585-90.

8 Harrington D, Coats AJ. Mechanisms of exercise intolerance in congestive heart failure. Curr Opin Cardiol 1997;12: ance in cong.

9 Richardson P, McKenna W, Bristow M, et al. Report of the 1995 World Health Organization/International Society and Federation of Cardiology task force on the definition and classification of cardiomyopathies. Circulation 1996;93: $841-2$.

10 Schiller NB, Shah PM, Crawford M, et al. Recommendations for quantitation of the left ventricle by twodimensional echocardiography. American Society of Echocardiography Committee on Standards, Subcommittee on Quantitation of Two-Dimensional Echocardiograms. $7 \mathrm{Am}$ Soc Echocardiogr 1989;2:358-67.

11 Jones N. Evaluation of a microprocessor-controlled exercise testing system. I Appl Physiol 1984;57:1312-19.

12 Jones NL, Summers E, Killian KJ. Influence of age and stature on exercise capacity during incremental cycle ergometry in men and women. Am Rev Respir Dis 1989;140: 1373-80.

13 Bruce RA, Kusumi F, Hosmer D. Maximal oxygen intake and nomographic assessment of functional aerobic impairment in cardiovascular disease. Am Heart $\mathcal{F}$ 1973;85:54662.

14 Cooper DM, Weiler-Ravell D, Whipp BJ, et al. Aerobic parameters of exercise as a function of body size during growth in children. 7 Appl Physiol 1984;56:628-34.

15 Astrand I, Astrand PO, Hallback I, et al. Reduction in maxiAstrand I, Astrand PO, Halloack I, et al. Reduction in maxi-
mal oxygen uptake with age. F Appl Physiol 1973;35:64954 .

16 Wasserman K, Hansen JE, Sue DY, et al. Principles of exercise testing and interpretation, 2nd ed. Philadelphia: Lee and Febiger, 1994:117-19.

17 Beaver WL, Wasserman K, Whipp BJ. A new method for detecting anaerobic threshold by gas exchange. $\mathcal{F} A p p l$ Physiol 1986;60:2020-7.

18 Hansen JE, Sue DY, Wasserman K. Predicted values for clinical exercise testing. Am Rev Respir Dis 1984;129:S4955.

19 Jones NL. Clinical exercise testing, 3rd ed. Philadelphia: WB Saunders, 1988.

20 Hansen JE, Sue DY, Oren A, et al. Relation of oxygen uptake as related to work rate increment during cycle ergometer as related to work rate increment during cycl
exercise. Eur $\mathcal{F}$ Appl Physiol 1988;57:140-5.

21 Jones NL. Clinical exercise testing, 3rd ed. Philadelphia: WB Saunders, 1988:306.

22 Wasserman K, Hansen JE, Sue DY, et al. Principles of exercise testing and interpretation, 2nd ed. Philadelphia: Lea and Febiger, 1994:117-19.

23 Jones S, Elliott PM, Sharma S, et al. Cardiopulmonary responses to exercise in patients with hypertrophic cardiomyopathy. Heart 1998;80:60-7.

24 Winter UJ, Gitt AK, Blaum M, et al. Cardiopulmonary capacity in patients with coronary heart disease. $Z$ Kardiol 1994;83(suppl 3):73-82. [In German.]

25 LeJemtel TH, Maskin CS, Lucido D, et al. Failure to augment maximal limb blood flow in response to one-leg versus two-leg exercise in patients with severe heart failure. Circulation 1986;74:245-51.

26 Hambrecht R, Niebauer J, Fiehn E, et al. Physical training in patients with stable chronic heart failure: effects on cardiorespiratory fitness and ultrastructural abnormalities of leg muscles. f Am Coll Cardiol 1995;25:1239-49.

27 Al-Rawas OA, Carter R, Richens D, et al. Ventilatory and gas exchange abnormalities on exercise in chronic heart failure. Eur Respir F 1995;8:2022-8

28 Banning AP, Lewis NP, Northridge DB, et al. Perfusion/ ventilation mismatch during exercise in chronic heart failure: an investigation of circulatory determinants. $\mathrm{Br}$ Heart f 1995; 74:27-33.

29 Chua TP, Coats AJ. The lungs in chronic heart failure. Eur Heart f 1995;16:882-7.

30 Sullivan MJ, Higginbotham MB, Cobb FR. Increased exercise ventilation in patients with chronic heart failure: intact ventilatory control despite hemodynamic and pulmonary ventilatory control despite hemodynamic

31 Chua TP, Clark AL, Amadi AA, et al. Relation between chemosensitivity and the ventilatory response to exercise in chronic heart failure. 7 Am Coll Cardiol 1996;27:650-7. 
32 Piepoli M, Clark AL, Volterrani M, et al. Contribution of muscle afferents to the hemodynamic, autonomic, and ventilatory responses to exercise in patients with chronic heart failure: effects of physical training. Circulation 1996;93:940-52.
33 Messner-Pellenc P, Brasileiro C, Ahmaidi S, et al. Exercise intolerance in patients with chronic heart failure: role of pulmonary

34 Sharma S, Elliot PM, Whyte G, et al. Cardiac dimensions in junior elite athletes. Heart 1998;79(suppl 1):40.

\title{
SHORT CASES IN CARDIOLOGY
}

\section{Mid-ventricular HOCM with apical asynergy}

\author{
J C Cooke, J M Cotton, M J Monaghan
}

A 45 year old woman presented with recurrent episodes of rapid non-sustained palpitations and associated dizziness. She had no significant medical history or family history of cardiac disease. Examination revealed a soft systolic murmur. ECG showed sinus rhythm with left ventricular hypertrophy on voltage criteria and inferolateral $\mathrm{T}$ wave changes. Transthoracic echocardiography demonstrated the unusual finding of mid-ventricular hypertrophic obstructive cardiomyopathy with systolic cavity obliteration at the papillary muscle level and an associated intracavity velocity of $4 \mathrm{~m} / \mathrm{s}$. There

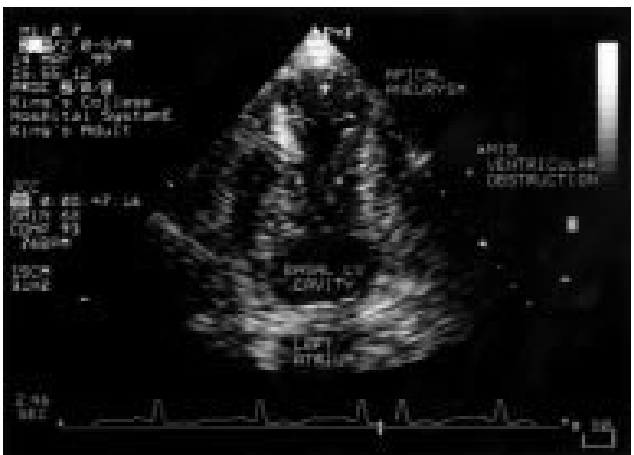

Figure 1 Apical two chamber view demonstrating mid-ventricular obstruction and an apical aneurysm.

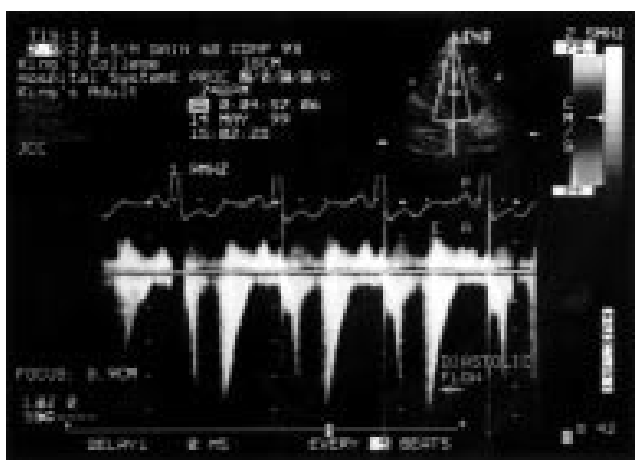

Figure 2 Continuous wave Doppler trace from an apical four chamber position revealing the mid-ventricular obstruction with cessation of flow followed by paradoxical early diastolic flow. was sparing of the basal septum and the apex was not hypertrophied but rather thinned, asynergic, and aneursymal (fig 1). No thrombus was evident and no other wall motion abnormalities were present. Colour Doppler revealed a turbulent jet in both systole and early diastole with flow from apex to base. Continuous wave Doppler (fig 2) revealed systolic flow away from the transducer (apical four chamber position), then mid-ventricular cavity obstruction with no flow, followed by a high early diastolic velocity $(4 \mathrm{~m} / \mathrm{s})$ and flow from apex to base concurrent with the mitral inflow $\mathrm{E}$ wave. This paradoxical early diastolic flow is thought to represent blood trapped in the apical cavity in systole, which subsequently leaves the apex in diastole when midventricular obstruction is no longer present.

Several patterns of hypertrophic cardiomyopathy (HCM) have now been clearly defined. The apical variant constitutes $25 \%$ of all HCM in the Japanese population, but only $1-2 \%$ of the HCM cases in non-Japanese patients. Midventricular HCM with apical asynergy is somewhat less common. In the largest published report to date, a Japanese team reported an incidence of concealed apical aneurysm with mid-ventricular cavity obliteration of approximately $1.5 \%$ of all HCM cases. The incidence in non-Japanese patients is yet to be clarified. The importance of this variant is its association with ventricular arrhythmias and systemic embolism, the latter occurring in $30 \%$ of patients. Identification of the paradoxical early diastolic flow from apex to base can be a marker of a sequestered apical chamber in patients with cavity obliteration, particularly when the apical cavity cannot readily be delineated by cross sectional echocardiography.

Following the echocardiographic findings in this patient, a 24 hour Holter monitor was performed and revealed self limiting runs of supraventricular tachycardia along with ventricular couplets, but no ventricular tachycardia. Her palpitations are now controlled on amiodarone. 